\title{
Ciliary Mechanisms of Cyst Formation in Polycystic Kidney Disease
}

\author{
Ming Ma, ${ }^{1}$ Anna-Rachel Gallagher, ${ }^{1}$ and Stefan Somlo ${ }^{1,2}$ \\ ${ }^{1}$ Department of Internal Medicine, Yale University School of Medicine, New Haven, Connecticut 06520-8029 \\ ${ }^{2}$ Department of Genetics, Yale University School of Medicine, New Haven, Connecticut 06520-8029 \\ Correspondence: stefan.somlo@yale.edu
}

\begin{abstract}
Autosomal-dominant polycystic kidney disease (ADPKD) is a disease of defective tissue homeostasis resulting in active remodeling of nephrons and bile ducts to form fluid-filled sacs called cysts. The causal genes PKD1 and PKD2 encode transmembrane proteins polycystin 1 (PC1) and polycystin 2 (PC2), respectively. Together, the polycystins localize to the solitary primary cilium that protrudes from the apical surface of most kidney tubule cells and is thought to function as a privileged compartment that the cell uses for signal integration of sensory inputs. It has been proposed that PC1 and PC2 form a receptor-channel complex that detects external stimuli and transmit a local calcium-mediated signal, which may control a multitude of cellular processes by an as-yet unknown mechanism. Genetic studies using mouse models of cilia and polycystin dysfunction have shown that polycystins regulate an unknown cilia-dependent signal that is normally part of the homeostatic maintenance of nephron structure. ADPKD ensues when this pathway is dysregulated by absence of polycystins from intact cilia, but disruption of cilia also disrupts this signaling mechanism and ameliorates ADPKD even in the absence of polycystins. Understanding the role of cilia and ciliary signaling in ADPKD is challenging, but success will provide saltatory advances in our understanding of how tubule structure is maintained in healthy kidneys and how disruption of polycystin or cilia function leads to the pathological tissue remodeling process underlying ADPKD.
\end{abstract}

\begin{abstract}
A utosomal dominant polycystic kidney disAease (ADPKD) is one of the most common human monogenic diseases with an occurrence of $\sim 1: 1000$ live births and more than 12 million people worldwide meeting radiographic diagnostic criteria for the disease. ADPKD patients develop cysts in the kidney that typically become clinically apparent by the fourth decade of life and increase in number and size over time, culminating in end-stage renal disease
\end{abstract}

(ESRD) in $\sim 50 \%$ of affected individuals in the sixth decade. Extrarenal cystic manifestations of ADPKD commonly include liver cysts, which arise from bile ducts. In the United States, $4 \%-5 \%$ of the prevalent ESRD population has ADPKD, which represents a significant burden to the patients, their families, and the health-care system. There are currently no approved therapies specifically targeting ADPKD in the United States.

Editors: Wallace Marshall and Renata Basto

Additional Perspectives on Cilia available at www.cshperspectives.org

Copyright (C) 2017 Cold Spring Harbor Laboratory Press; all rights reserved; doi: 10.1101/cshperspect.a028209

Cite this article as Cold Spring Harb Perspect Biol 2017;9:a028209 
M. Ma et al.

The causal genes for ADPKD are PKD1 and $P K D 2$, encoding polycystin 1 (PC1) and polycystin 2 (PC2), respectively (The European Polycystic Kidney Disease Consortium 1994; The International Polycystic Kidney Disease Consortium 1995; Mochizuki et al. 1996). PC1 and PC2 are multimembrane-spanning proteins that interact with each other through their respective carboxy-terminal coiled-coil domains (Qian et al. 1997). Mature forms of both proteins localize to the primary cilium, a minute membrane-encased microtubule-based structure that protrudes from the apical surface of kidney tubule epithelial cells (Pazour et al. 2002; Yoder et al. 2002) that is used by cells as a sensory organelle for signal integration. Mutations in PKD1 account for $\sim 78 \%$ of ADPKD cases, mutations in PKD2 account for the $\sim 15 \%$ of cases, and the remaining $7 \%-8 \%$ of cases have no mutation detected in either gene (Audrezet et al. 2012; Heyer et al. 2016). PC1 is a 4302-amino-acid protein consisting of a large $\sim 3000$-amino-acid extracellular domain, 11 transmembrane domains, and an intracellular carboxyl terminus. PC1 undergoes autoproteolytic G-protein-coupled receptor proteolytic site (GPS) cleavage in the endoplasmic reticulum (ER) (Qian et al. 2002; Yu et al. 2007), which requires the structural integrity of the GPCR autoproteolysis-inducing (GAIN) domain (Arac et al. 2012; Tesmer 2012). This generates an amino-terminal fragment $(\mathrm{PC} 1-\mathrm{NTF})$ and a carboxy-terminal fragment $(\mathrm{PC} 1-\mathrm{CTF})$ that remains associated and they traffic together to the primary cilium (Cai et al. 2014; Kim et al. 2014; Gainullin et al. 2015). Additional subcellular locations have been reported for PC1 at the apical membrane and the lateral membrane, as well as in desmosomes (Ibraghimov-Beskrovnaya et al. 1997; Scheffers et al. 2000; Chapin et al. 2010).

PC2 has been described as a nonselective calcium permeable cation channel belonging to the transient receptor potential (TRP) channel family (Koulen et al. 2002), although direct measurement of its wild-type channel properties has not yet been achieved (DeCaen et al. 2013; Delling et al. 2013). PC2 has six transmembrane domains with a cytoplasmic $\mathrm{NH}_{2}$ and carboxyl termini. The carboxyl terminus contains a coiled-coil domain that facilitates its interaction with PC1 (Tsiokas et al. 1997) and an EF-hand for calcium binding (Mochizuki et al. 1996; Celic et al. 2008). The amino terminus contains an $\mathrm{RVxP}$ motif that is important for targeting PC2 to the cilium (Geng et al. 2006). The carboxyl terminus contains a putative interaction domain that retains PC2 in the ER (Cai et al. 1999), and interaction with PC1 is required for full-length PC2 to leave the ER and reach the cilium (Kim et al. 2014; Gainullin et al. 2015). PC2 is serine/threonine phosphorylated in the carboxyl terminus and the phosphorylation changes the calcium activation properties of the channel measured in lipid bilayers and the trafficking of PC2 in cultured cells (Cai et al. 2004; Kottgen et al. 2005; Plotnikova et al. 2011; Streets et al. 2013). The in vivo physiological role of PC2 phosphorylation, including its potential role in the pathogenesis of $A D P K D$, remains to be determined.

ADPKD is typically transmitted as a dominant trait by loss-of-function alleles in PKD1 or $P K D 2$. Cyst initiation in ADPKD generally occurs by somatic "second-hit" mutations that inactivate the normal copy of the respective disease gene rendering it recessive at the cellular level (Qian et al. 1996; Watnick et al. 1998; Wu et al. 1998; Pei et al. 1999). Because the second hits are stochastic and can occur throughout life and throughout the kidney, cysts are focal and varied in size. This may, in part, account for the substantial intrafamilial clinical variation in ADPKD families, although genetic modifiers may also contribute to clinical variation. Recessive inheritance of hypomorphic PKD1 alleles has been reported with clinical presentation of more homogeneous polycystic kidneys (Rossetti et al. 2009). Polycystic kidney disease progresses more rapidly in PKD1 patients than PKD2 patients. Individual cysts grow exponentially (Grantham et al. 2006). The rate of cyst growth in PKD1 and PKD2 are similar and the difference in severity is largely accounted for by the presence of more cysts early in life of $P K D 1$ compared with $\mathrm{PKD} 2$ patients (Harris et al. 2006). This implicates cyst initiation, rather than cyst expansion, as the main determinant 
of disease progression rate (Grantham et al. 2008). Because the PKD1 coding sequence is four times as long as that of $P K D 2$, it is expected to sustain more second hits contributing to increased cyst initiation events.

Rather than being an all-or-none phenomenon, cyst formation has been shown to be a continuum that is dependent on the degree of functional impairment of PC1, which serves as the rate limiting step in the PC1-PC2 complex (Fedeles et al. 2011, 2014). The functional dosage of PC1 (and PC2) in human polycystic diseases can be modulated by several factors. The most extreme level is total loss of function, which occurs when both the germline PKD gene mutation and the second hit mutation result in complete loss of functional polycystin protein. A subset of germline nonsynonymous amino-acid substitution mutations in PC1 have reduced but not absent function (i.e., hypomorphic alleles), and these result in a milder course for ADPKD (Hopp et al. 2012; Cornec-Le Gall et al. 2013; Heyer et al. 2016). These hypomorphic alleles typically produce intact $\mathrm{PC} 1$ protein that may be relatively deficient in one of several putative functions. Changes that may lead to reduced function include relative decrease in the steady-state expression of PC1, defects in cleavage at the GPS, or impaired trafficking to cilia (Fedeles et al. 2011; Hopp et al. 2012; Cai et al. 2014). These features may not be entirely independent. For example, a recent study showed that mutations in the GAIN domain that abrogate GPS cleavage also impair cilia trafficking both in vivo and in vitro (Cai et al. 2014). Mutations in amino-terminal domains that do not affect GPS cleavage can nonetheless impair cilia trafficking, whereas mutations in the extracellular IgG-like PKD domains allow both cleavage and trafficking to cilia yet still result in a loss of function (Cai et al. 2014).

Other factors have also been shown to affect cyst growth. Cysts generated in utero grow extraordinarily fast as evidenced by monitoring cyst volume of individual cysts using magnetic resonance for more than 3 years (Grantham et al. 2010). Similarly, mouse genetic models of ADPKD show that cyst growth rates are much faster when Pkd gene inactivation occurs during kidney development than when it occurs in adult kidneys (Piontek et al. 2007). Different cell types and nephron segments in the kidney also have different cyst growth potential. Collecting duct cysts develop much faster and predominate over cysts originating in other nephron segments (Wu et al. 1998; Shibazaki et al. 2008; Fedeles et al. 2011). Although most models showing this rely on Cre recombinasemediated gene inactivation, predominance of collecting duct cysts was also observed in $P k d 2^{w s 25 /-}$ mice (Wu et al. 1998). This model has an unstable allele that undergoes stochastic, rather than enzymatic, somatic inactivation, which eliminates any bias introduced by activity properties of the latter. Evidence suggests that collecting duct cysts also predominate in human ADPKD (Torres et al. 2012).

\section{A UNIFYING THEORY OF CILIARY DYSFUNCTION UNDERLIES CYST FORMATION?}

Cilia structural and compositional abnormalities underlie a wide range of recessive fibrocystic genetic diseases including nephronophthisis, Joubert syndrome, Meckel-Gruber syndrome, and Bardet-Biedl syndrome (Gerdes et al. 2009; Hildebrandt et al. 2011). These diseases are collectively termed "ciliopathies" and have pleiotropic manifestations in many organs, including fibrosis and cyst formation in the kidney and liver. It is important to note that all of the ciliopathies are recessively inherited. The primary cilium is a pivotal organelle for the pathogenesis of cystic kidney diseases. Almost all eukaryotic cells have a primary cilium. The cilium is connected with transition zone and basal body, which functionally separate the cilia compartment and its overlying membrane from the rest of the cell body and apical membrane of epithelial cells. Signaling molecules express on the ciliary membrane and mediate sensory signal inputs to detect and transmit stimuli from outside the cell (Menco et al. 1997; Corbit et al. 2005; Rohatgi et al. 2007). The protein products of many ciliopathy disease genes localize to the cilia-basal body complex (Hildebrandt et al. 2009; Jin et al. 2010; Garcia-Gonzalo et al. 
M. Ma et al.

2011; Sang et al. 2011). Recessive fibrocystic kidney phenotypes can be produced by genetic models that result in total loss of cilia (Lin et al. 2003; Weatherbee et al. 2009), in structural abnormalities of cilia (Bielas et al. 2009; Cui et al. 2011), and disturbance of membrane protein composition in cilia (Nishimura et al. 2004; Eichers et al. 2006; Garcia-Gonzalo et al. 2011). These data led to a unifying hypothesis that the mechanism of cyst formation in different genetic diseases is a result of cilia dysfunction, including abnormalities in cilia structure, composition, and signaling (Watnick and Germino 2003; Hildebrandt and Otto 2005; Hildebrandt and Zhou 2007). In this formulation, the detailed molecular mechanisms for individual diseases were lacking, and it was hard to know whether the exact function of cilia for each disease was independent of the others or had a more complex relationship.

Although cysts share some similarities across all polycystic kidney and liver diseases, the histopathological features and cellular events associated with the different diseases are not identical. The ADPKD cysts are focal and originate from all segments of the nephron. The autosomal recessive polycystic kidney disease cysts are fusiform and originate exclusively in the collecting duct. Kidney cysts in nephronophthisis are typically located in the corticomedullary junctional region and are associated with extensive fibrosis at earlier stages (Hildebrandt and Zhou 2007). Epithelial cell proliferation is associated with cyst formation in mouse models of ADPKD, whereas apoptosis is not apparent in cyst-lining cells (Shibazaki et al. 2008; Ma et al. 2013). In kidney cysts of pcy and $j c k$ mice, the respective genetic models of Nphp3 and Nphp9, extensive apoptosis is observed in addition to epithelial cell proliferation (Omori et al. 2006; Smith et al. 2006). The different cellular events and histopathology associated with the different cystic diseases imply that distinct molecular mechanisms may underlie cyst formation in different forms of disease. Furthermore, heterozygous carrier adults for the ciliopathy disorders are typically asymptomatic throughout life. Presumably, second hits also affect the normal alleles in the adult heterozygous ciliopathy gene carriers, but they do not result in a discernible clinical phenotype during adult life. Additionally, conditional genetic removal of cilia in the kidney tubules of rodents result in a cystic phenotype in both early-onset and adult models (Lin et al. 2003; Davenport et al. 2007), but cysts progress at a much slower pace than in $P k d 1$ conditional mutants models in which only a single cilia component protein is removed (Piontek et al. 2007; Shibazaki et al. 2008). ADPKD may be related to ciliopathy disorders by virtue of the ciliary location of the affected gene products, but it is genetically and mechanistically distinct from ciliopathies. Together, these and other findings suggested that the mechanisms of ADPKD and ciliopathies may be distinct.

\section{CILIA STIMULATE CYST GROWTH IN ADPKD MODELS}

Experimental support for a distinct mechanistic relationship between polycystins and cilia came from studies showing that removing cilia in mouse models of $P k d 1$ or $P k d 2$ inactivation suppresses cyst growth (Ma et al. 2013). Conditional mouse models in which cilia and either $P k d 1$ or $P k d 2$ were inactivated in the same population of cells in kidney tubules and liver bile ducts showed that removal of cilia suppresses cyst growth in both early and adult-inactivation models in both organs (Ma et al. 2013). Cilia-dependent cyst growth was applicable to all nephron segments, including proximal tubule, medullary thick ascending loop of Henle, and collecting duct. Loss of polycystins results in slow, but elevated, proliferation rates compared with wild-type kidney tubule epithelia. This increased proliferation is a marker for disease progression, but is likely not sufficient to generate cysts as a forced expression of Cuxl in cilia (Ift88) mutant kidney does not increase cysts (Sharma et al. 2013). The increased proliferation in ADPKD models is suppressed in cilia-polycystin double mutants (Ma et al. 2013). Transgenic overexpression of PC1 in vivo in a cilia mutant did not have an impact on cystic burden, suggesting that the cysts resulting from cilia removal were independent of $\mathrm{PC} 1$ function 
(Ma et al. 2013; Wills et al. 2014). Finally, the severity of the polycystic kidney disease in the cilia-polycystin double knockouts is directly correlated to the length of time between the initial disappearance of polycystin protein and the subsequent involution of preformed cilia (Ma et al. 2013).

Together, these findings provide genetic evidence for an unidentified ciliary signal(s) termed cilia-dependent cyst activation (CDCA), which is dependent on intact cilia for activity and is normally inhibited by the functioning of polycystins (Fig. 1) (Ma et al. 2013). CDCA is presumably derepressed in a regulated manner by the normal physiological function of polycystins, although the nature of this physiological role is unknown. Following somatic second hit inactivation of polycystins, CDCA becomes constitutively and pathologically derepressed if intact cilia persist, giving rise to ADPKD (Fig. 1). The aggregate data indicate that cilia-dependent cyst growth is a universal mechanism of cyst formation in ADPKD because of mutations in $P k d 1$ and $P k d 2$. This suggests that it is essential when testing therapeutic compounds for ADPKD to use orthologous models and to reasonably expect that an effective preclinical intervention should work in both early and late inactivation models, $P k d 1$ and $P k d 2$ models, all nephron segments, and the bile duct as well.

\section{WHAT DOES CDCA DO?}

What may the physiological role of CDCA be? One hypothesis may be that it is a dynamic regulator of nephron tubule lumen diameter and of nephron tubule epithelial cell morphology (Fig. 1). Under normal conditions, PC1PC2-regulated CDCA achieves a dynamic balance to modulate tubule lumen diameter and epithelial-lining cell shape under different physiological conditions including, perhaps, altered luminal flow rate or ligand binding. PC1 is the rate limiting component for CDCA and likely encodes a graded signal whose functional activity is dependent on the quantitative nature of the signal input or PC1 dosage (Fedeles et al. 2011, 2014; Hopp et al. 2012). When PC1 - PC2 signaling is attenuated below a certain threshold by mutation (Fedeles et al. 2011; Hopp et al. 2012), inhibition of CDCA is chronically weakened. Under normal conditions, polycystin-dependent loss of inhibition is reversible when the signal to reduce polycystin function is reversed. In the case of chronically weakened of absent polycystin function, the otherwise reversible process becomes indolent and persistent and tubules begin to remodel the surrounding basement membranes and parenchyma with attendant cell proliferation and change in morphology eventually causing cysts to form.

\section{MAMMALIAN HEDGEHOG SIGNALING AND THE POTENTIAL COMPLEXITY OF CDCA}

The biggest challenge in understanding the cellular molecular mechanisms of ADPKD is to discover the specific local polycystin-regulated signaling processes that occur in cilia. One paradigm for the operation of CDCA-polycystin signaling in cilia may be found in the mammalian Hedgehog ( $\mathrm{Hh}$ ) signaling pathway, in which cilia play an essential, but complex, role. The molecular components of Hh signaling were originally uncovered from a genetic screen for segment polarity mutants in Drosophila melanogaster larvae (Nusslein-Volhard and Wieschaus 1980). Forward genetic screens in the mouse identified the primary cilium to be essential for the mammalian Hh pathway particularly in neural tubule patterning (Huangfu et al. 2003). Almost all known conserved $\mathrm{Hh}$ pathway components, including Patched1 (Ptch) (Rohatgi et al. 2007), Smoothened (Corbit et al. 2005), Gli2, Gli3 (Huangfu and Anderson 2005), suppressor of fused (Sufu) (Haycraft et al. 2005), and Kif7 (He et al. 2014), localize to the cilia. In the absence of Hh ligand, Ptch is expressed on primary cilia and the signaling is shut off. When Hh ligand binds to ciliary Ptch, Ptch exits the cilia, allowing Smoothened to translocate into the cilia and transduce downstream signaling (Corbit et al. 2005; Rohatgi et al. 2007). Cilia are also required for generating the functional forms of downstream Gli proteins, including generating the truncated func- 
M. Ma et al.
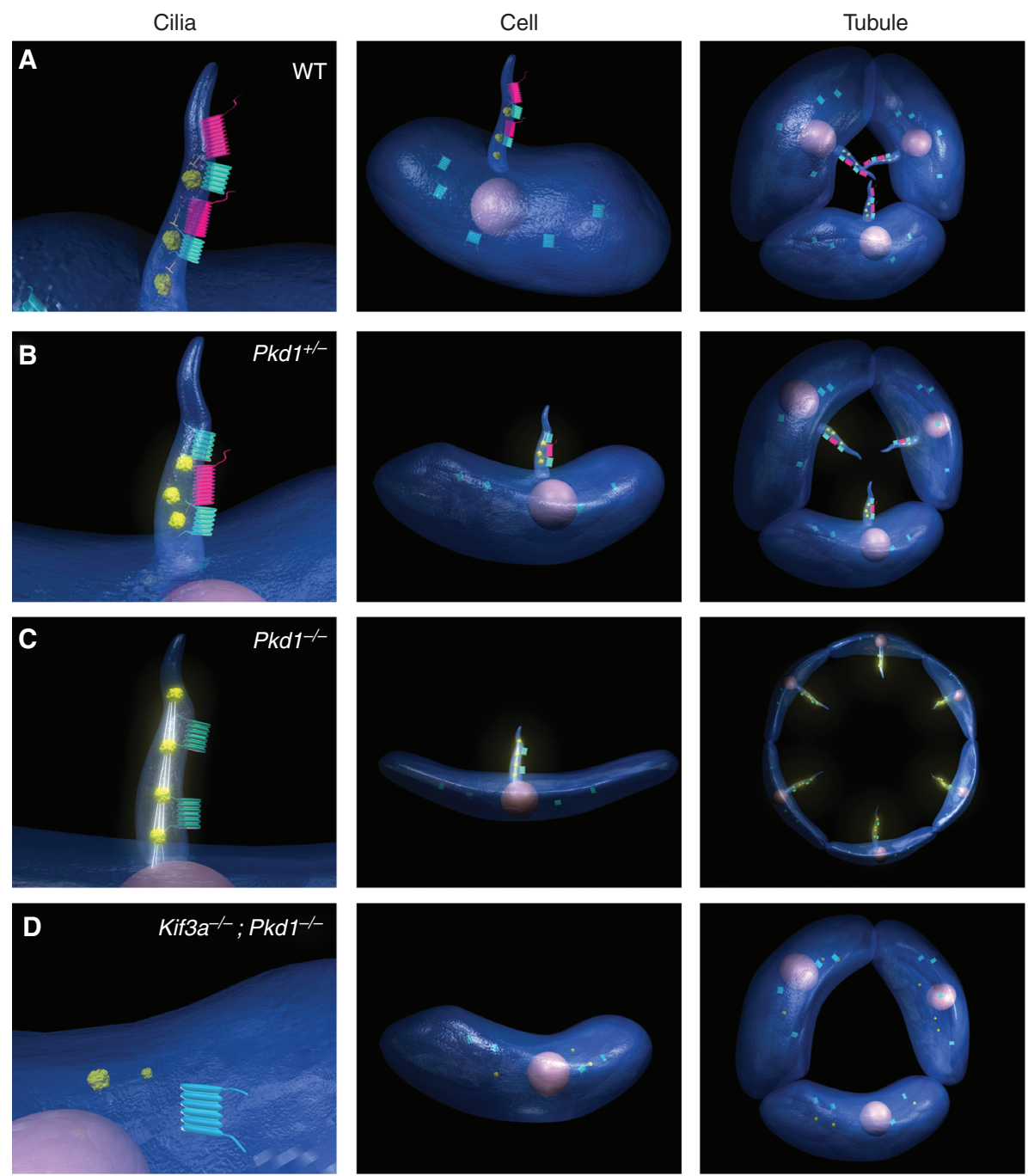

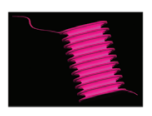

PC1

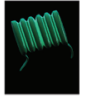

PC2

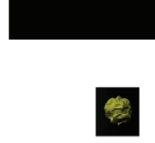

Quiescent CDCA

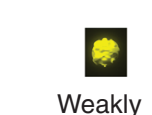

activated CDCA

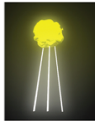

Activated CDCA

Figure 1. Schematic illustration of polycystin 1 (PC1)-polycystin 2 (PC2)-cilia-dependent cyst activation (CDCA) signaling. (A) The PC1-PC2 complex is expressed in cilia and maintains CDCA in a physiologically regulated quiescent state with epithelial cells retaining a columnar shape and the tubule with normal lumen diameter. Normal physiological input would adjust CDCA to physiological needs of cell shape, lumen morphology, cell transport, metabolic properties, etc. WT, Wild type. (B) Reduced PC1 dosage in heterozygous cells of autosomal-dominant polycystic kidney disease (ADPKD) patients may lead to weak constitutive activation of CDCA and a modest steady-state change in cell shape (less columnar) and lumen diameter (increased). (C) Loss of PC1 in the presence of intact cilia, the condition for cyst initiation in ADPKD, leads to inexorable activation of CDCA, profound changes in cells to a more squamoid shape, low-level proliferation, active remodeling of surrounding kidney parenchyma, and growth of cysts. Note that the images of cells and tubules (cysts) in panel $C$ are at a much lower illustrative "magnification" than $A, B$, or $D$. (D) Loss of cilia in the absence of PC1 markedly reduces the activation of CDCA and maintains cell shape and tubule lumen diameter in a more normal range. 
tional repressor form of Gli3R (Haycraft et al. 2005; Huangfu and Anderson 2005). Primary cilia have been shown to both mediate and suppress $\mathrm{Hh}$ pathway-dependent tumorigenesis (Han et al. 2009; Wong et al. 2009). The primary cilium does not participate in the signaling per se; rather, it is a signal integration compartment that positively and negatively regulates the signaling events that are transduced (Goetz and Anderson 2010; Ocbina et al. 2011). To draw the analogy to Hh signaling, the normal physiological function of PC1 and PC2 in cilia is an inhibitory signal, like that of Ptch. Ptch mutants result in unchecked activation of the Hh pathway (Goodrich et al. 1997), whereas in Ptchcilia double mutants, this activation is attenuated (Huangfu et al. 2003). This has parallels to what is observed in polycystin mutants and polycystin-cilia double mutant. Given the complexity of the components of Hh downstream from Ptch, one may begin to get an appreciation of the potential nuances of CDCA. A critical step toward understanding CDCA will be the improved discovery of the other proteins present in cilia (Mukhopadhyay et al. 2013; Mick et al. 2015).

\section{CYST FORMATION IN OTHER CILIOPATHIES IN RELATION TO PC1-PC2-CDCA BALANCE}

The cystic phenotypes in nephronophthisis, Joubert syndrome, Meckel-Gruber syndrome, and Bardet-Biedl syndrome might be the result of imbalance of CDCA-PC1-PC2 signaling pathway in cilia. The gene products involved for the recessive fibrocystic disorders in part regulate structural architecture and composition of cilia and centrosomes through control of trafficking of proteins in and out of these compartments (Garcia-Gonzalo et al. 2011). The animal models for the recessive ciliopathies develop less severe cystic disease than ADPKD models (Nishimura et al. 2004; Eichers et al. 2006; Omori et al. 2006; Davenport et al. 2007; Weatherbee et al. 2009). Such an outcome may be the result of compromised polycystin-mediated inhibitory function resulting in modest activation of CDCA as opposed to unchecked activation of CDCA resulting in more aggressive cyst growth in ADPKD models (Piontek et al. 2007; Shibazaki et al. 2008). The less severe kidney disease observed in the recessive ciliopathy models than that in ADPKD mouse models may be analogous to the less severe neural tube dorsoventral patterning defect seen in the cilia structural mutants than in Ptch mutants (Goetz and Anderson 2010).

Polycystins and ciliary CDCA components are likely the cargo and targets of the transition zone sorting and gating machinery subsumed by some of the recessive ciliopathy gene products. It has been shown that some mutations in ciliary gating machinery components result in defective trafficking of ciliary membrane proteins, including Smoothened and PC2 (Garcia-Gonzalo et al. 2011). In this context, polycystins and CDCA might not traffic sufficiently to cilia and thus generate a slow forming cystic phenotype. Interestingly $\mathrm{PC} 1$ is reported to interact with BBS1, BBS4, BBS5, and BBS8 and ciliary $\mathrm{PC} 1$ expression is reduced in BBS1 knockdown cells and BBS3 mutant cells ( $\mathrm{Su}$ et al. 2014). These findings support the possibility that relative PC1 deficiency may underlie a component of the cystic kidney phenotype in Bardet-Biedl syndrome. Based on this hypothesis, it would be expected the overexpression of physiologically active PC1 would be able to ameliorate the kidney cystic phenotypes in some of the recessive ciliopathy mutants in a manner analogous to what has been shown for isolated polycystic liver diseases (Fedeles et al. 2011).

\section{CILIARY SIGNALING PATHWAYS AS CANDIDATES FOR CDCA}

The cilium is essential for the signal transduction of a number of signaling pathways, any of which may be candidate pathways for CDCA. There also exist a plethora of proteins that localize to the cilium, but whose roles in cilia signal transduction are not fully understood. CDCA may well be among these unknown pathways. Here, we briefly discuss the known cilia associated signaling pathways and comment on their roles as candidates for CDCA and ADPKD. 
M. Ma et al.

\section{Hedgehog Signaling}

Recent studies have described genetic interaction of the Hh signaling pathway with cystic kidney diseases models. These findings raise the question of whether Smoothened could be a component of CDCA and could Hh signaling modulate the CDCA-PC1-PC2 to control ADPKD? Hh pathway transcriptional target genes are elevated in Thm1 (IFT complex A) and jck (Nphp9, Nek8) cystic kidneys and in kidneys of an early inactivation model of $P k d 1$ (Tran et al. 2014). Reduced Gli2 activity slowed cyst growth in the Thm 1 mutant kidney. In Pkd2l1 mutant cilia, where ciliary calcium signaling is impaired as had been hypothesized (but not shown) for PC1-PC2 mutants, Hh agonist- mediated expression of Glil is reduced and cilia tip localization of Gli2 is diminished (Delling et al. 2013). Examination of the Pkd2l1 mutant mice shows low penetrance of a gut looping chirality defect, a process dependent on Hh signaling (Zhang et al. 2001; Delling et al. 2013). Therefore, ciliary polycystin paralogs and some recessive ciliopathy genes modulate ciliary Hh signaling. Nonetheless, the contribution of $\mathrm{Hh}$ signaling to cyst formation in $\mathrm{ADPKD}$ remains an open question that is worth resolving, especially in adult-onset ADPKD models. If inactivation of $\mathrm{Hh}$ pathway suppresses cyst growth in adult-onset ADPKD models, this would suggest that Hh signaling promotes cyst progression making it a candidate for CDCA.

\section{cAMP}

Elevated cAMP levels have been associated with ADPKD, ARPKD ( pck), and NPHP ( $p c y)$ rodent models and vasopressin receptor 2 antagonist administration slows cyst growth in these models (Gattone et al. 2003; Torres et al. 2004). Moreover, a competitive vasopressin receptor 2 antagonist has undergone human clinical trials with some reduction in kidney volume in ADPKD patients (Torres et al. 2012), although the drug has not been approved for use in ADPKD in the United States. Studies have shown that PC2 and phosphodiesterase 4C are components of a ciliary A-kinase-anchoring protein complex that is disrupted in the absence of $P k d 2$ (Choi et al. 2011). Interestingly, conditional inactivation of the cilia-expressed adenylyl cyclase 6 (AC6) concomitantly with inactivation of $\mathrm{Pkd} 1$ in the collecting duct reduces cystic burden in an early-onset model of ADPKD (Rees et al. 2014). These findings suggest that further studies are needed to evaluate whether AC6 and cAMP inhibition are also effective in other nephron segments, in adult-onset models and in other organs like liver-features that would suggest they may be central to CDCA in ADPKD. Even if that is not the case, because a large portion of cysts in human ADPKD are derived from the collecting duct in which cAMP activation has been observed, blocking this pathway genetically or pharmacologically remains an attractive target (Torres et al. 2004, 2012; Rees et al. 2014).

\section{Ciliary Lkb1 and mTOR Signaling}

Mammalian target of rapamycin (mTOR) signaling integrates the nutrient, oxygen, and energy state of the cells and controls cell growth, proliferation, and survival. The Lkb1-AMPK branch of this pathway negatively regulates mTOR activity. Lkb1 localizes to the primary cilium and regulates mTORC1 activity and cell size in response to flow (Boehlke et al. 2010). In this model, inactivation of PC2 reduced calcium transients in cells but had no effect on ciliadependent mTORC1 activation. Ciliary Lkb1mediated mTORC1 signaling is independent of PC2 signaling and Lkb1 is less likely to be part of the CDCA pathway (Boehlke et al. 2010). mTOR signaling is also unlikely to be candidate of CDCA because loss of PC1 is not sufficient to activate mTOR. Activation of this pathway is mosaic in cyst-lining epithelia that are completely devoid of $P k d 1$ (Shillingford et al. 2006, 2010). In another study, mTOR activation was not observed in an adult-onset ADPKD model at both precystic and cystic stage when CDCA was active (Ma et al. 2013). The mosaic activation of mTOR signaling in cyst-lining cells, however, could serve as a booster for cyst growth in ADPKD. Pharmacological inhibition of the mTOR pathway ameliorates cystic burden in 
ADPKD mouse models (Shillingford et al. 2010) but has yet to prove beneficial in ADPKD patients perhaps because of limitations in delivering the needed dose to the kidney (Serra et al. 2010; Torres et al. 2010; Walz et al. 2010).

\section{Ciliary PDGFR $\alpha \alpha$ and MAPK/ERK Signaling}

PDGFR $\alpha \alpha$ (PdgfrAA) is expressed in the primary cilia of fibroblast cells and on treatment with PDGF ligand, phosphorylation of PdgfrAA, and phospho-MEK1/2 is detected in cilia (Schneider et al. 2005). It has been shown that the activation of PdgfrAA is reduced in Ift88 mutant Tg737 fibroblast cells that have short and stumpy cilia compared with that in control cells, showing the integrity of cilia is required for efficient activation of the pathway (Schneider et al. 2005). The PdgfrAA pathway in animal models of ADPKD has not been directly evaluated for a role in cyst initiation or progression. MAPK/ERK signaling is not likely to be CDCA as its activation is mainly restricted to the distal nephron and at later stages of cyst formation in ADPKD models (Shibazaki et al. 2008; Ma et al. 2013). Moreover, attenuation of the MAPK/ERK pathway pharmacologically has no impact on cyst progression in a developmental model of ADPKD, although the effects of longer-term therapy could not be evaluated (Shibazaki et al. 2008). MAPK/ERK activation is found in cyst lining cells of $p c y$ (Nphp3) mice and blocking activation of the pathway with an inhibitor attenuates cyst progression in these animals (Omori et al. 2006). Thus MAPK/ERK signaling acts as a driver for cyst progression in some ciliopathy models model, but not ADPKD models.

\section{Extracellular Matrix and Integrin Signaling}

Multiple genetic interactions between polycystin signaling and extracellular matrix (ECM) components have been shown in a number of organ systems including the kidney. Knockdown of $P k d 1 a / b$ and $P k d 2$ in zebrafish results in collagen deposition in the notochord and generates the curly tail "up" phenotype (Mangos et al. 2010), a commonly observed charac- teristic in cilia defective mutants (Sun et al 2004). Another ECM protein, fibrillin, encoded by FBN1, which is the causal gene in Marfan syndrome, has been shown to genetically interact with $P k d 1$. Pkd1 and Fbn1 compound heterozygote mice exacerbate vascular complications observed in Fbn1 heterozygotes resulting in increased TGF- $\beta$ signaling. Inactivation of $P k d 1$ in the vascular smooth muscle cells is sufficient to generate vascular complications associated with elevated TGF- $\beta$ signaling (Liu et al. 2014). More direct evidence of ECM signaling involvement in the pathogenesis of ADPKD came from the recent finding that inactivation of $\beta 1$-integrin suppresses cyst formation in a developmental model of ADPKD (Lee et al. 2014). In vitro knockdown of $\beta 1$-integrin reduces cyst formation by $P k d 1$ knockdown cells in a matrix-gel model (Subramanian et al. 2012). Interestingly, multiple integrin receptors are expressed in primary cilia of MDCK cells (Praetorius et al. 2004) and chondrocytes (McGlashan et al. 2007) and $\beta 1$-integrin has been localized to cilia in the rat kidney. Ciliary $\beta 1$-integrin has been shown in MDCK cells to potentiate fibronectin-induced calcium signaling (Praetorius et al. 2004). Considering that the removal of $\beta 1$-integrin ameliorates the cystic phenotype in the early inactivation model of $P k d 1$ (Lee et al. 2014), further studies on the role of $\beta 1$-integrin in adult-onset models of ADPKD would be reasonable. If confirmed, investigation of the ciliary $\beta 1$-integrin as a candidate for CDCA may be indicated.

\section{THE MECHANOSENSOR HYPOTHESIS FOR POLYCYSTINS IN CILIA}

PC1 has been hypothesized to have receptortype function on cilia. It has long been proposed to be a flow sensor (Nauli et al. 2003) although recent studies have called that into question (Delling et al. 2016). More recently, it has been proposed to be a Wnt ligand coreceptor (Kim et al. 2016). A common downstream effect as part of these hypotheses is polycystin-regulated calcium entry through the PC1-PC2 complex. The recent development of direct channel measurements by patch clamping of 
M. Ma et al.

cilia and of genetically encoded calcium sensors targeted to cilia have begun to allow more direct measurement and visualization of intraciliary calcium transients under different physiological conditions (DeCaen et al. 2013; Delling et al. 2013; Su et al. 2013; Jin et al. 2014). Studies directly measuring channel activity on the surface of cilia have been unable to detect the PC1 - PC2 channel activity (DeCaen et al. 2013) and have instead argued that ciliary calcium entry could not be the cellular signaling event of polycystin action emerging from cilia (Delling et al. 2013; Delling et al. 2016). Specifically, primary cilia of human retinal pigment epithelial cells and other cells are specialized calcium signaling organelles whose resting calcium concentration is up to sevenfold higher than cytosolic calcium (DeCaen et al. 2013). The intracilia calcium appears to be regulated by $\mathrm{Pkd} 112-$ $\mathrm{Pkd} 211$, and not the anticipated PC1 - PC2 complex (Delling et al. 2013). Ciliary Pkd112$\mathrm{Pkd} 2 \mathrm{ll}$ is essential for efficient activation of Hh signaling via modulating the expression of Gli1 and Gli2 localization at the ciliary tip. $P k d 2 l 1$ mutant mice display low penetrance of gut looping chirality defect, a process dependent on Hh signaling during development (Delling et al. 2013). Applying physiologically relevant levels of mechanical force to bend or deflect cilia resulted in no alteration of calcium transients in cilia of the kidney tubule and other cell types (Delling et al. 2016). Laminar flow applied to ciliated cells generates shear stress and initiates calcium transients in the cytoplasm, which then propagate to the cilia (Delling et al. 2016), not vice versa. Delling et al. (2016) propose that the mechanosensation function of cilia, if it exists, is through mediators other than whole cell calcium transients. It is possible that PC2 exerts its function via allosteric transfer of calcium ion from PC1-PC2 to other signaling molecules, like CDCA components in the local context of the cilium, but massive cellular calcium transients are not required.

Polycystins, particularly PC2, function in other tissues aside from the kidney and liver. One example is in the vertebrate embryonic node where the left-right axis is established during early embryonic development (Nonaka et al. 1998; Essner et al. 2002; Pennekamp et al. 2002; McGrath et al. 2003). In mammals, the motile cilia at the center of the node propel fluid to generate leftward flow, and the crown cells at the periphery of the node express PC2 on nonmotile cilia that may sense this flow (McGrath et al. 2003; Yoshiba et al. 2012). Loss of PC2 results in abnormal left-right axis formation (Pennekamp et al. 2002). Reexpression of PC2 specifically in the crown cells in $P k d 2$ mutant nodes is sufficient to initiate lateralized Nodal and Pitx2 expression, and ciliary localization of PC2 is required for this process (Yoshiba et al. 2012). $P k d 111$, a homolog of $P k d 1$, may act as the partner with PC2 in nodal cilia. Together, they play a role in establishing the left-right axis, a function that is conserved in vertebrates (Vogel et al. 2010; Field et al. 2011; Kamura et al. 2011). In cell culture systems, artificial flow can deflect cilia and trigger intraciliary calcium transients (Su et al. 2013). Live imaging of calcium transients in zebrafish Kupffer's vesicle (KV), the zebrafish counterpart of mouse embryonic node, shows that calcium transients propagate from cilia to the cytoplasm of the crown cells on the left side of the KV and that the calcium transients oscillate over time followed by lateralized gene expression (Yuan et al. 2015). These calcium transients are highly reduced in $P k d 2$ knockdown embryos or when motile cilia are paralyzed. Introduction of cilia-targeted genetically encoded calcium chelators dampen ciliary calcium transients and generate left-right defective embryos. The investigators conclude that intraciliary calcium mediated by PC2 is essential to initiate left-right axis determination in zebrafish (Yuan et al. 2015).

A number of salient differences in the experimental systems used could in part explain the disparate ciliary calcium kinetics in these studies (DeCaen et al. 2013; Delling et al. 2013; Su et al. 2013; Jin et al. 2014; Yuan et al. 2015). The differences in combinatorial pairing of ciliary PC1 and PC2 or their respective homologs might generate different calcium responses that are further specialized by cell and tissue type to meet specific physiologic functional requirements. The differences in channel activity and transients between mouse epithelial 
cells and fish KV may be a result of physiological differences between stationary primary cilia in the mammalian cells and the active motile cilia in KV in zebrafish (Becker-Heck et al. 2011). Furthermore, the milieu in cell culture experiments and the fluid in the KV have different compositions of chemical and bioactive molecules. The differences in observed activity may also stem from incomplete knowledge of biological and physiological regulators of the respective cilia channels. Nonetheless, the genetically encoded calcium indicators and chelators and the technical advances in patch clamping offer novel physiological tools to measure the in vivo intraciliary calcium transients in kidney and liver and relate PC1 - PC2 function to physiological properties of cilia. These advances will help dissect the function of the intracilia calcium and polycystins across a spectrum of biological systems in the future.

\section{HOW DOES PC1 REGULATE CDCA?}

Given the unique structural features of PC1 and the importance of GPS cleavage to its function (Qian et al. 2002; Yu et al. 2007; Cai et al. 2014), it is worth considering hypotheses based on the functional inferences from other GPS cleaved proteins. Adhesion G-protein-coupled receptors (aGPCR) are a class of GPCRs that are characterized by a large extracellular domain (ECD), seven transmembrane spans (7TM), and a GAIN/GPS domain located near the junction of the ECD and the first transmembrane domain. GAIN/GPS domain containing aGPCRs undergo autoproteolytic cleavage to generate ECD and 7TM that associate with each other noncovalently (Liebscher et al. 2013), in a manner analogous to what has been proposed for $\mathrm{PC1}$. ECD dissociation from the $7 \mathrm{TM}$ is thought to result in activation of disparate downstream G protein signaling by GPR56 and GPR110, implicating that the association of ECD with 7TM is autoinhibitory (Stoveken et al. 2015). The ECD displacement unmasks the amino-terminal stalk regions of 7TM, which serve as autoligands essential for $\mathrm{G}$ protein signaling (Stoveken et al. 2015). A missense variant (p.C492Y) in the GAIN domain of another
aGPCR, ADGRE2 (EMR2), weakens the ECD and 7TM autoinhibitory interaction and sensitizes mast cells to vibration-induced degranulation in a familial form vibratory urticaria (Boyden et al. 2016).

The autoinhibitory action of ECD on 7TM in aGPCR could have implications for how PC1-NTF may regulate PC1-CTF and how their dynamic interactions regulate CDCA to control target phenotypes such as lumen diameter or kidney epithelial cell shape (Fig. 2). Strong association of PC1-NTF with PC1CTF suppresses the activation of CDCA. Either ligand binding or mechanical stimuli such as luminal flow may trigger stimulus dosage-dependent displacement of PC1-NTF from PC1-CTF, which could unmask the amino-terminal stalk region of PC1-CTF. This stalk protein could act as an autoactivating ligand to relieve PC1 - CTF inhibition of CDCA with consequent downstream activation of CDCA-dependent changes in the tubule epithelial cells. The PC1 signal can be turned off either by reassociation of PC1-NTF with PC1-CTF or, if the signal deactivation has a longer time course, by removal of the unbound PC1-CTF from cilia and its replacement with intact PC1NTF/CTF complex. The latter model would seem more likely in cilia projecting into the urinary space of the nephron lumen. In the case of $\mathrm{ADPKD}$, when there is little or no PC1 present in the cilia, the net effect of this absence is the same as having PC1-CTF present but dissociated from $\mathrm{PC} 1-\mathrm{NTF}$. It is the intact $\mathrm{PC} 1-\mathrm{NTF} /$ CTF complex that keeps CDCA in check. The identification of CDCA and the study of its interaction with PC1 and PC2 may explain how tubule lumen diameter or cell shape or differentiation state is dynamically fine-tuned to meet the demand of various physiological conditions and how unchecked CDCA activation leads to the indolent, but profound tissue remodeling processes that underlie ADPKD.

\section{CONCLUSION}

Polycystic kidney diseases encompass a broad spectrum of genetic diseases. Cysts can develop via nonidentical and nonoverlapping cellular 
M. Ma et al.

A
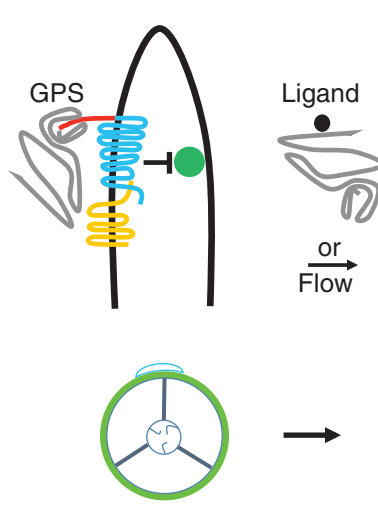

Tubule cell shape and lumen diameter
B
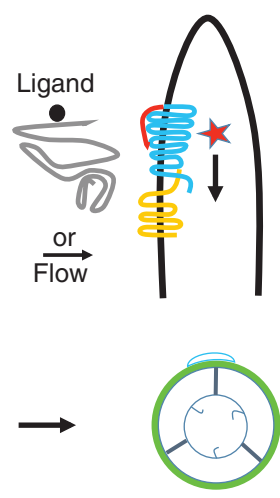

C
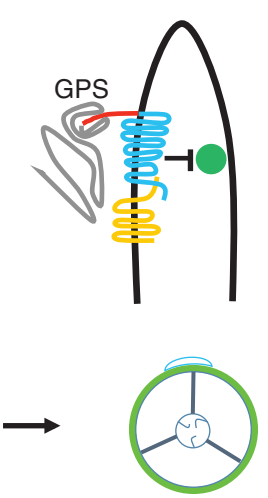

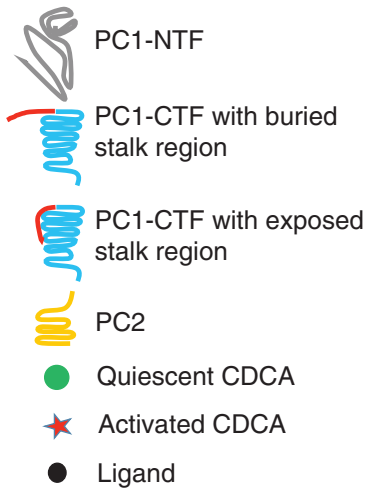

Figure 2. Model of PC1 regulation after GPS cleavage. (A) Following G-protein-coupled receptor proteolytic site (GPS) cleavage, PC1 - NTF and PC1-CTF remain associated with each other and traffic to cilia where the PC1PC2 complex maintains cilia-dependent cyst activation (CDCA) in a regulated quiescent state. $(B)$ In the presence of a stimulus, either ligand binding or mechanical input such as flow, PC1-NTF is displaced from PC1-CTF. This exposes the buried stalk region of PC1-CTF (red), which may serve as an autoligand that releases PC1-CTF inhibition of CDCA. Transient activation of CDCA leads to alterations in cell shape and lumen diameter (bottom panels). ( $C$ ) Either reassociation of PC1-NTF with PC1-CTF or retrieval of unbound $\mathrm{PC} 1-\mathrm{CTF}$ from cilia and its replacement with $\mathrm{PC} 1-\mathrm{NTF} / \mathrm{CTF}-\mathrm{PC} 2$ complex returns CDCA to a reduced state of activity and the tubules to a baseline morphology.

events, which implies different molecular mechanisms for the pathogenesis of each group or class of disease entity. The pathogenetic mechanism of each disease requires focused investigation. In the case of ADPKD caused by mutations in PKD1 or PKD2, the protective role of loss of cilia suggests that the PC1-PC2 complex serves to regulate a ciliary signaling pathway(s) (CDCA) that is necessary to drive cyst growth when either polycystin is inactivated. This serves as a strong proof of concept that targeting the components of CDCA should slow cyst growth. The challenge remains in discovering CDCA, whose components most likely localize to and function in cilia. The advances in generation and use of animal models, the development of novel biological tools such as ciliatargeted genetically encoded calcium sensors and chelators and enhanced cilia proteomics, and the improved understanding of the biochemical properties of polycystins and related proteins offer exciting prospects for novel discoveries for the next phase of understanding and eventually treating ADPKD.

\section{ACKNOWLEDGMENTS}

We apologize to the community that many papers could not be cited because of space limitations. We thank Zhaoning Liu for artwork. This work is supported by grants to S.S. from the National Institutes of Health (NIH) (R01 DK54053 and R01 DK100592) and the Lillian Goldman Charitable Trust. M.M. and A.-R.G. are supported by Polycystic Kidney Disease Foundation Research Grants-in-Aid (51ga13 and 46ga13).

\section{REFERENCES}

Arac D, Boucard AA, Bolliger MF, Nguyen J, Soltis SM, Sudhof TC, Brunger AT. 2012. A novel evolutionarily conserved domain of cell-adhesion GPCRs mediates autoproteolysis. EMBO J 31: 1364-1378.

Audrezet MP, Cornec-Le Gall E, Chen JM, Redon S, Quere I, Creff J, Benech C, Maestri S, Le Meur Y, Ferec C. 2012. Autosomal dominant polycystic kidney disease: Comprehensive mutation analysis of PKD1 and PKD2 in 700 unrelated patients. Hum Mutat 33: $1239-1250$.

Becker-Heck A, Zohn IE, Okabe N, Pollock A, Lenhart KB, Sullivan-Brown J, McSheene J, Loges NT, Olbrich H, 
Haeffner K, et al. 2011. The coiled-coil domain containing protein CCDC40 is essential for motile cilia function and left-right axis formation. Nat Genet 43: 79-84.

Bielas SL, Silhavy JL, Brancati F, Kisseleva MV, Al-Gazali L, Sztriha L, Bayoumi RA, Zaki MS, Abdel-Aleem A, Rosti RO, et al. 2009. Mutations in INPP5E, encoding inositol polyphosphate-5-phosphatase E, link phosphatidyl inositol signaling to the ciliopathies. Nat Genet 41: 10321036.

Boehlke C, Kotsis F, Patel V, Braeg S, Voelker H, Bredt S, Beyer T, Janusch H, Hamann C, Godel M, et al. 2010. Primary cilia regulate mTORC1 activity and cell size through Lkb1. Nat Cell Biol 12: 1115-1122.

Boyden SE, Desai A, Cruse G, Young ML, Bolan HC, Scott LM, Eisch AR, Long RD, Lee CC, Satorius CL, et al. 2016. Vibratory urticaria associated with a missense variant in ADGRE2. N Engl J Med 374: 656-663.

Cai Y, Maeda Y, Cedzich A, Torres VE, Wu G, Hayashi T, Mochizuki T, Park JH, Witzgall R, Somlo S. 1999. Identification and characterization of polycystin-2, the PKD2 gene product. J Biol Chem 274: 28557-28565.

Cai Y, Anyatonwu G, Okuhara D, Lee KB, Yu Z, Onoe T, Me CL, Qian Q, Geng L, Wiztgall R, et al. 2004. Calcium dependence of polycystin-2 channel activity is modulated by phosphorylation at Ser812. J Biol Chem 279: 19987-19995.

Cai Y, Fedeles SV, Dong K, Anyatonwu G, Onoe T, Mitobe M, Gao JD, Okuhara D, Tian X, Gallagher AR, et al. 2014 Altered trafficking and stability of polycystins underlie polycystic kidney disease. J Clin Invest 124: 5129-5144.

Celic A, Petri ET, Demeler B, Ehrlich BE, Boggon TJ. 2008. Domain mapping of the polycystin-2 C-terminal tail using de novo molecular modeling and biophysical analysis. J Biol Chem 283: 28305-28312.

Chapin HC, Rajendran V, Caplan MJ. 2010. Polycystin-1 surface localization is stimulated by polycystin-2 and cleavage at the $\mathrm{G}$ protein-coupled receptor proteolytic site. Mol Biol Cell 21: 4338-4348.

Choi YH, Suzuki A, Hajarnis S, Ma Z, Chapin HC, Caplan MJ, Pontoglio M, Somlo S, Igarashi P. 2011. Polycystin-2 and phosphodiesterase $4 \mathrm{C}$ are components of a ciliary Akinase anchoring protein complex that is disrupted in cystic kidney diseases. Proc Natl Acad Sci 108: 1067910684.

Corbit KC, Aanstad P, Singla V, Norman AR, Stainier DY, Reiter JF. 2005. Vertebrate smoothened functions at the primary cilium. Nature 437: 1018-1021.

Cornec-Le Gall E, Audrezet MP, Chen JM, Hourmant M, Morin MP, Perrichot R, Charasse C, Whebe B, Renaudineau E, Jousset P, et al. 2013. Type of PKD1 mutation influences renal outcome in ADPKD. J Am Soc Nephrol 24: $1006-1013$.

Cui C, Chatterjee B, Francis D, Yu Q, SanAgustin JT, Francis R, Tansey T, Henry C, Wang B, Lemley B, et al. 2011. Disruption of Mks1 localization to the mother centriole causes cilia defects and developmental malformations in Meckel-Gruber syndrome. Dis Model Mech 4: 43-56.

Davenport JR, Watts AJ, Roper VC, Croyle MJ, van Groen T, Wyss JM, Nagy TR, Kesterson RA, Yoder BK. 2007. Disruption of intraflagellar transport in adult mice leads to obesity and slow-onset cystic kidney disease. Curr Biol 17: 1586-1594.
DeCaen PG, Delling M, Vien TN, Clapham DE. 2013. Direct recording and molecular identification of the calcium channel of primary cilia. Nature 504: 315-318.

Delling M, DeCaen PG, Doerner JF, Febvay S, Clapham DE. 2013. Primary cilia are specialized calcium signalling organelles. Nature 504: 311-314.

Delling M, Indzhykulian AA, Liu X, Li Y, Xie T, Corey DP, Clapham DE. 2016. Primary cilia are not calcium-responsive mechanosensors. Nature 531: 656-660.

Eichers ER, Abd-El-Barr MM, Paylor R, Lewis RA, Bi W, Lin X, Meehan TP, Stockton DW, Wu SM, Lindsay E, et al. 2006. Phenotypic characterization of Bbs4 null mice reveals age-dependent penetrance and variable expressivity. Hum Genet 120: 211-226.

Essner JJ, Vogan KJ, Wagner MK, Tabin CJ, Yost HJ, Brueckner M. 2002. Conserved function for embryonic nodal cilia. Nature 418: 37-38.

Fedeles SV, Tian X, Gallagher AR, Mitobe M, Nishio S, Lee SH, Cai Y, Geng L, Crews CM, Somlo S. 2011. A genetic interaction network of five genes for human polycystic kidney and liver diseases defines polycystin- 1 as the central determinant of cyst formation. Nat Genet 43: 639-647.

Fedeles SV, Gallagher AR, Somlo S. 2014. Polycystin-1: A master regulator of intersecting cystic pathways. Trends Mol Med 20: 251-260.

Field S, Riley KL, Grimes DT, Hilton H, Simon M, PowlesGlover N, Siggers P, Bogani D, Greenfield A, Norris DP. 2011. Pkd111 establishes left-right asymmetry and physically interacts with $P k d 2$. Development 138: 1131-1142.

Gainullin VG, Hopp K, Ward CJ, Hommerding CJ, Harris PC. 2015. Polycystin-1 maturation requires polycystin-2 in a dose-dependent manner. J Clin Invest 125: 607-620.

Garcia-Gonzalo FR, Corbit KC, Sirerol-Piquer MS, Ramaswami G, Otto EA, Noriega TR, Seol AD, Robinson JF, Bennett CL, Josifova DJ, et al. 2011. A transition zone complex regulates mammalian ciliogenesis and ciliary membrane composition. Nat Genet 43: 776-784.

Gattone VH II, Wang X, Harris PC, Torres VE. 2003. Inhibition of renal cystic disease development and progression by a vasopressin V2 receptor antagonist. Nat Med 9 : $1323-1326$.

Geng L, Okuhara D, Yu Z, Tian X, Cai Y, Shibazaki S, Somlo S. 2006. Polycystin-2 traffics to cilia independently of polycystin-1 by using an N-terminal RVxP motif. J Cell Sci 119: 1383-1395.

Gerdes JM, Davis EE, Katsanis N. 2009. The vertebrate primary cilium in development, homeostasis, and disease. Cell 137: 32-45.

Goetz SC, Anderson KV. 2010. The primary cilium: A signalling centre during vertebrate development. Nat Rev Genet 11: 331-344.

Goodrich LV, Milenkovic L, Higgins KM, Scott MP. 1997. Altered neural cell fates and medulloblastoma in mouse patched mutants. Science 277: 1109-1113.

Grantham JJ, Torres VE, Chapman AB, Guay-Woodford LM, Bae KT, King BF Jr, Wetzel LH, Baumgarten DA, Kenney PJ, Harris PC, et al. 2006. Volume progression in polycystic kidney disease. N Engl J Med 354: 21222130.

Grantham JJ, Cook LT, Torres VE, Bost JE, Chapman AB, Harris PC, Guay-Woodford LM, Bae KT. 2008. Determi- 
M. Ma et al.

nants of renal volume in autosomal-dominant polycystic kidney disease. Kidney Int 73: 108-116.

Grantham JJ, Cook LT, Wetzel LH, Cadnapaphornchai MA, Bae KT. 2010. Evidence of extraordinary growth in the progressive enlargement of renal cysts. Clin J Am Soc Nephrol 5: 889-896.

Han YG, Kim HJ, Dlugosz AA, Ellison DW, Gilbertson RJ, Alvarez-Buylla A. 2009. Dual and opposing roles of primary cilia in medulloblastoma development. Nat Med 15: $1062-1065$.

Harris PC, Bae KT, Rossetti S, Torres VE, Grantham JJ, Chapman AB, Guay-Woodford LM, King BF, Wetzel LH, Baumgarten DA, et al. 2006. Cyst number but not the rate of cystic growth is associated with the mutated gene in autosomal dominant polycystic kidney disease. $J$ Am Soc Nephrol 17: 3013-3019.

Haycraft CJ, Banizs B, Aydin-Son Y, Zhang Q, Michaud EJ, Yoder BK. 2005. Gli2 and Gli3 localize to cilia and require the intraflagellar transport protein polaris for processing and function. PLoS Genet 1: e53.

He M, Subramanian R, Bangs F, Omelchenko T, Liem KF Jr, Kapoor TM, Anderson KV. 2014. The kinesin-4 protein Kif7 regulates mammalian Hedgehog signalling by organizing the cilium tip compartment. Nat Cell Biol 16: 663-672.

Heyer CM, Sundsbak JL, Abebe KZ, Chapman AB, Torres VE, Grantham JJ, Bae KT, Schrier RW, Perrone RD, Braun WE, et al. 2016. Predicted mutation strength of nontruncating PKD1 mutations aids genotype-phenotype correlations in autosomal dominant polycystic kidney disease. J Am Soc Nephrol doi: 10.1681/ASN.2015050583.

Hildebrandt F, Otto E. 2005. Cilia and centrosomes: A unifying pathogenic concept for cystic kidney disease? Nat Rev Genet 6: 928-940.

Hildebrandt F, Zhou W. 2007. Nephronophthisis-associated ciliopathies. J Am Soc Nephrol 18: 1855-1871.

Hildebrandt F, Attanasio M, Otto E. 2009. Nephronophthisis: Disease mechanisms of a ciliopathy. J Am Soc Nephrol 20: $23-35$.

Hildebrandt F, Benzing T, Katsanis N. 2011. Ciliopathies. N Engl J Med 364: 1533-1543.

Hopp K, Ward CJ, Hommerding CJ, Nasr SH, Tuan HF, Gainullin VG, Rossetti S, Torres VE, Harris PC. 2012. Functional polycystin-1 dosage governs autosomal dominant polycystic kidney disease severity. J Clin Invest 122: 4257-4273.

Huangfu D, Anderson KV. 2005. Cilia and Hedgehog responsiveness in the mouse. Proc Natl Acad Sci 102: $11325-11330$.

Huangfu D, Liu A, Rakeman AS, Murcia NS, Niswander L, Anderson KV. 2003. Hedgehog signalling in the mouse requires intraflagellar transport proteins. Nature 426: 83-87.

Ibraghimov-Beskrovnaya O, Dackowski WR, Foggensteiner L, Coleman N, Thiru S, Petry LR, Burn TC, Connors TD, Van Raay T, Bradley J, et al. 1997. Polycystin: In vitro synthesis, in vivo tissue expression, and subcellular localization identifies a large membrane-associated protein. Proc Natl Acad Sci 94: 6397-6402.

Jin H, White SR, Shida T, Schulz S, Aguiar M, Gygi SP, Bazan JF, Nachury MV. 2010. The conserved Bardet-Biedl syn- drome proteins assemble a coat that traffics membrane proteins to cilia. Cell 141: 1208-1219.

Jin X, Mohieldin AM, Muntean BS, Green JA, Shah JV, Mykytyn K, Nauli SM. 2014. Cilioplasm is a cellular compartment for calcium signaling in response to mechanical and chemical stimuli. Cell Mol Life Sci 71: 2165-2178.

Kamura K, Kobayashi D, Uehara Y, Koshida S, Iijima N, Kudo A, Yokoyama T, Takeda H. 2011. Pkd111 complexes with Pkd2 on motile cilia and functions to establish the left-right axis. Development 138: 1121-1129.

Kim H, Xu H, Yao Q, Li W, Huang Q, Outeda P, Cebotaru V, Chiaravalli M, Boletta A, Piontek K, et al. 2014. Ciliary membrane proteins traffic through the Golgi via a Rabep1/GGA1/Arl3-dependent mechanism. Nat Commun 5: 5482 .

Kim S, Nie H, Nesin V, Tran U, Outeda P, Bai CX, Keeling J, Maskey D, Watnick T, Wessely O, et al. 2016. The polycystin complex mediates Wnt $/ \mathrm{Ca}^{2+}$ signalling. Nat Cell Biol 18: 752-764.

Kottgen M, Benzing T, Simmen T, Tauber R, Buchholz B, Feliciangeli S, Huber TB, Schermer B, Kramer-Zucker A, Hopker K, et al. 2005. Trafficking of TRPP2 by PACS proteins represents a novel mechanism of ion channel regulation. EMBO J 24: 705-716.

Koulen P, Cai Y, Geng L, Maeda Y, Nishimura S, Witzgall R, Ehrlich BE, Somlo S. 2002. Polycystin-2 is an intracellular calcium release channel. Nat Cell Biol 4: 191-197.

Lee K, Boctor S, Barisoni LM, Gusella GL. 2014. Inactivation of integrin- $\beta 1$ prevents the development of polycystic kidney disease after the loss of polycystin-1. J Am Soc Nephrol 26: 888-895.

Liebscher I, Schoneberg T, Promel S. 2013. Progress in demystification of adhesion $\mathrm{G}$ protein-coupled receptors. Biol Chem 394: 937-950.

Lin F, Hiesberger T, Cordes K, Sinclair AM, Goldstein LS, Somlo S, Igarashi P. 2003. Kidney-specific inactivation of the KIF3A subunit of kinesin-II inhibits renal ciliogenesis and produces polycystic kidney disease. Proc Natl Acad Sci 100: 5286-5291.

Liu D, Wang CJ, Judge DP, Halushka MK, Ni J, Habashi JP, Moslehi J, Bedja D, Gabrielson KL, Xu H, et al. 2014. A Pkd1-Fbn1 genetic interaction implicates TGF- $\beta$ signaling in the pathogenesis of vascular complications in autosomal dominant polycystic kidney disease. J Am Soc Nephrol 25: 81-91.

Ma M, Tian X, Igarashi P, Pazour GJ, Somlo S. 2013. Loss of cilia suppresses cyst growth in genetic models of autosomal dominant polycystic kidney disease. Nat Genet 45: 1004-1012.

Mangos S, Lam PY, Zhao A, Liu Y, Mudumana S, Vasilyev A, Liu A, Drummond IA. 2010. The ADPKD genes $p k d 1 a / b$ and $p k d 2$ regulate extracellular matrix formation. Dis Model Mech 3: 354-365.

McGlashan SR, Haycraft CJ, Jensen CG, Yoder BK, Poole CA. 2007. Articular cartilage and growth plate defects are associated with chondrocyte cytoskeletal abnormalities in $\mathrm{Tg} 737^{\text {orpk }}$ mice lacking the primary cilia protein polaris. Matrix Biol 26: 234-246.

McGrath J, Somlo S, Makova S, Tian X, Brueckner M. 2003. Two populations of node monocilia initiate left-right asymmetry in the mouse. Cell 114: 61-73. 
Menco BP, Cunningham AM, Qasba P, Levy N, Reed RR 1997. Putative odour receptors localize in cilia of olfactory receptor cells in rat and mouse: A freeze-substitution ultrastructural study. J Neurocytol 26: 691-706.

Mick DU, Rodrigues RB, Leib RD, Adams CM, Chien AS, Gygi SP, Nachury MV. 2015. Proteomics of primary cilia by proximity labeling. Dev Cell 35: 497-512.

Mochizuki T, Wu G, Hayashi T, Xenophontos SL, Veldhuisen B, Saris JJ, Reynolds DM, Cai Y, Gabow PA, Pierides A, et al. 1996. PKD2, a gene for polycystic kidney disease that encodes an integral membrane protein. Science 272: $1339-1342$.

Mukhopadhyay S, Wen X, Ratti N, Loktev A, Rangell L, Scales SJ, Jackson PK. 2013. The ciliary G-protein-coupled receptor Gpr161 negatively regulates the Sonic hedgehog pathway via cAMP signaling. Cell 152: 210 223.

Nauli SM, Alenghat FJ, Luo Y, Williams E, Vassilev P, Li X, Elia AE, Lu W, Brown EM, Quinn SJ, et al. 2003. Polycystins 1 and 2 mediate mechanosensation in the primary cilium of kidney cells. Nat Genet 33: 129-137.

Nishimura DY, Fath M, Mullins RF, Searby C, Andrews M, Davis R, Andorf JL, Mykytyn K, Swiderski RE, Yang B, et al. 2004. Bbs2-null mice have neurosensory deficits, a defect in social dominance, and retinopathy associated with mislocalization of rhodopsin. Proc Natl Acad Sci 101: 16588-16593.

Nonaka S, Tanaka Y, Okada Y, Takeda S, Harada A, Kanai Y, Kido M, Hirokawa N. 1998. Randomization of left-right asymmetry due to loss of nodal cilia generating leftward flow of extraembryonic fluid in mice lacking KIF3B motor protein. Cell 95: 829-837.

Nusslein-Volhard C, Wieschaus E. 1980. Mutations affecting segment number and polarity in Drosophila. Nature 287: 795-801.

Ocbina PJ, Eggenschwiler JT, Moskowitz I, Anderson KV 2011. Complex interactions between genes controlling trafficking in primary cilia. Nat Genet 43: 547-553.

Omori S, Hida M, Fujita H, Takahashi H, Tanimura S, Kohno M, Awazu M. 2006. Extracellular signal-regulated kinase inhibition slows disease progression in mice with polycystic kidney disease. J Am Soc Nephrol 17: 16041614.

Pazour GJ, San Agustin JT, Follit JA, Rosenbaum JL, Witman GB. 2002. Polycystin-2 localizes to kidney cilia and the ciliary level is elevated in orpk mice with polycystic kidney disease. Curr Biol 12: R378-380.

Pei Y, Watnick T, He N, Wang K, Liang Y, Parfrey P, Germino G, St George-Hyslop P. 1999. Somatic PKD2 mutations in individual kidney and liver cysts support a "two-hit" model of cystogenesis in type 2 autosomal dominant polycystic kidney disease. J Am Soc Nephrol 10: 15241529.

Pennekamp P, Karcher C, Fischer A, Schweickert A, Skryabin B, Horst J, Blum M, Dworniczak B. 2002. The ion channel polycystin-2 is required for left-right axis determination in mice. Curr Biol 12: 938-943.

Piontek K, Menezes LF, Garcia-Gonzalez MA, Huso DL, Germino GG. 2007. A critical developmental switch defines the kinetics of kidney cyst formation after loss of Pkd1. Nat Med 13: 1490-1495.
Plotnikova OV, Pugacheva EN, Golemis EA. 2011. Aurora A kinase activity influences calcium signaling in kidney cells. J Cell Biol 193: 1021-1032.

Praetorius HA, Praetorius J, Nielsen S, Frokiaer J, Spring KR. 2004. $\beta 1$-integrins in the primary cilium of MDCK cells potentiate fibronectin-induced $\mathrm{Ca}^{2+}$ signaling. $\mathrm{Am} \mathrm{J}$ Physiol Renal Physiol 287: F969-978.

Qian F, Watnick TJ, Onuchic LF, Germino GG. 1996. The molecular basis of focal cyst formation in human autosomal dominant polycystic kidney disease type I. Cell 87: 979-987.

Qian F, Germino FJ, Cai Y, Zhang X, Somlo S, Germino GG. 1997. PKD1 interacts with PKD2 through a probable coiled-coil domain. Nat Genet 16: 179-183.

Qian F, Boletta A, Bhunia AK, Xu H, Liu L, Ahrabi AK, Watnick TJ, Zhou F, Germino GG. 2002. Cleavage of polycystin-1 requires the receptor for egg jelly domain and is disrupted by human autosomal-dominant polycystic kidney disease 1-associated mutations. Proc Natl Acad Sci 99: 16981-16986.

Rees S, Kittikulsuth W, Roos K, Strait KA, Van Hoek A, Kohan DE. 2014. Adenylyl cyclase 6 deficiency ameliorates polycystic kidney disease. JAm Soc Nephrol 25: 232 237.

Rohatgi R, Milenkovic L, Scott MP. 2007. Patched1 regulates hedgehog signaling at the primary cilium. Science 317 : 372-376.

Rossetti S, Kubly VJ, Consugar MB, Hopp K, Roy S, Horsley SW, Chauveau D, Rees L, Barratt TM, van't Hoff WG, et al. 2009. Incompletely penetrant $P K D 1$ alleles suggest a role for gene dosage in cyst initiation in polycystic kidney disease. Kidney Int 75: 848-855.

Sang L, Miller JJ, Corbit KC, Giles RH, Brauer MJ, Otto EA, Baye LM, Wen X, Scales SJ, Kwong M, et al. 2011. Mapping the NPHP-JBTS-MKS protein network reveals ciliopathy disease genes and pathways. Cell 145: 513-528.

Scheffers MS, van der Bent P, Prins F, Spruit L, Breuning MH, Litvinov SV, de Heer E, Peters DJ. 2000. Polycystin1 , the product of the polycystic kidney disease 1 gene, colocalizes with desmosomes in MDCK cells. Hum Mol Genet 9: 2743-2750.

Schneider L, Clement CA, Teilmann SC, Pazour GJ, Hoffmann EK, Satir P, Christensen ST. 2005. PDGFR $\alpha \alpha$ signaling is regulated through the primary cilium in fibroblasts. Curr Biol 15: 1861-1866.

Serra AL, Poster D, Kistler AD, Krauer F, Raina S, Young J, Rentsch KM, Spanaus KS, Senn O, Kristanto P, et al. 2010 Sirolimus and kidney growth in autosomal dominant polycystic kidney disease. N Engl J Med 363: 820-829.

Sharma N, Malarkey EB, Berbari NF, O'Connor AK, Vanden Heuvel GB, Mrug M, Yoder BK. 2013. Proximal tubule proliferation is insufficient to induce rapid cyst formation after cilia disruption. J Am Soc Nephrol 24: 456-464.

Shibazaki S, Yu Z, Nishio S, Tian X, Thomson RB, Mitobe M, Louvi A, Velazquez H, Ishibe S, Cantley LG, et al. 2008. Cyst formation and activation of the extracellular regulated kinase pathway after kidney specific inactivation of Pkd1. Hum Mol Genet 17: 1505-1516.

Shillingford JM, Murcia NS, Larson CH, Low SH, Hedgepeth R, Brown N, Flask CA, Novick AC, Goldfarb DA, Kramer-Zucker A, et al. 2006. The mTOR pathway is regulated by polycystin- 1 , and its inhibition reverses renal 
M. Ma et al.

cystogenesis in polycystic kidney disease. Proc Natl Acad Sci 103: 5466-5471.

Shillingford JM, Piontek KB, Germino GG, Weimbs T. 2010. Rapamycin ameliorates PKD resulting from conditional inactivation of Pkd1. J Am Soc Nephrol 21: 489-497.

Smith LA, Bukanov NO, Husson H, Russo RJ, Barry TC, Taylor AL, Beier DR, Ibraghimov-Beskrovnaya O. 2006. Development of polycystic kidney disease in juvenile cystic kidney mice: Insights into pathogenesis, ciliary abnormalities, and common features with human disease. J Am Soc Nephrol 17: 2821-2831.

Stoveken HM, Hajduczok AG, Xu L, Tall GG. 2015. Adhesion $\mathrm{G}$ protein-coupled receptors are activated by exposure of a cryptic tethered agonist. Proc Natl Acad Sci 112: 6194-6199.

Streets AJ, Wessely O, Peters DJ, Ong AC. 2013. Hyperphosphorylation of polycystin-2 at a critical residue in disease reveals an essential role for polycystin-1-regulated dephosphorylation. Hum Mol Genet 22: 1924-1939.

Su S, Phua SC, DeRose R, Chiba S, Narita K, Kalugin PN, Katada T, Kontani K, Takeda S, Inoue T. 2013. Genetically encoded calcium indicator illuminates calcium dynamics in primary cilia. Nat Methods 10: 1105-1107.

Su X, Driscoll K, Yao G, Raed A, Wu M, Beales PL, Zhou J. 2014. Bardet-Biedl syndrome proteins 1 and 3 regulate the ciliary trafficking of polycystic kidney disease 1 protein. Hum Mol Genet 23: 5441-5451.

Subramanian B, Ko WC, Yadav V, DesRochers TM, Perrone RD, Zhou J, Kaplan DL. 2012. The regulation of cystogenesis in a tissue engineered kidney disease system by abnormal matrix interactions. Biomaterials 33: $8383-$ 8394 .

Sun Z, Amsterdam A, Pazour GJ, Cole DG, Miller MS, Hopkins N. 2004. A genetic screen in zebrafish identifies cilia genes as a principal cause of cystic kidney. Development 131: 4085-4093.

Tesmer JJ. 2012. A GAIN in understanding autoproteolytic $G$ protein-coupled receptors and polycystic kidney disease proteins. EMBO J 31: 1334-1335.

The European Polycystic Kidney Disease Consortium. 1994. The polycystic kidney disease 1 gene encodes a $14 \mathrm{~kb}$ transcript and lies within a duplicated region on chromosome 16. Cell 78: 725.

The International Polycystic Kidney Disease Consortium. 1995. Polycystic kidney disease: The complete structure of the PKD1 gene and its protein. Cell 81: 289-298.

Torres VE, Wang X, Qian Q, Somlo S, Harris PC, Gattone VH II. 2004. Effective treatment of an orthologous model of autosomal dominant polycystic kidney disease. Nat Med 10: 363-364.

Torres VE, Boletta A, Chapman A, Gattone V, Pei Y, Qian Q, Wallace DP, Weimbs T, Wuthrich RP. 2010. Prospects for mTOR inhibitor use in patients with polycystic kidney disease and hamartomatous diseases. Clin J Am Soc Nephrol 5: 1312-1329.

Torres VE, Chapman AB, Devuyst O, Gansevoort RT, Grantham JJ, Higashihara E, Perrone RD, Krasa HB, Ouyang J, Czerwiec FS, et al. 2012. Tolvaptan in patients with autosomal dominant polycystic kidney disease. $N$ Engl J Med 367: 2407-2418.
Tran PV, Talbott GC, Turbe-Doan A, Jacobs DT, Schonfeld MP, Silva LM, Chatterjee A, Prysak M, Allard BA, Beier DR. 2014. Downregulating hedgehog signaling reduces renal cystogenic potential of mouse models. J Am Soc Nephrol 25: 2201-2212.

Tsiokas L, Kim E, Arnould T, Sukhatme VP, Walz G. 1997. Homo- and heterodimeric interactions between the gene products of PKD1 and PKD2. Proc Natl Acad Sci 94: 6965-6970.

Vogel P, Read R, Hansen GM, Freay LC, Zambrowicz BP, Sands AT. 2010. Situs inversus in $\mathrm{Dpcd} / \mathrm{Poll}^{-/-}$, $\mathrm{Nme}^{-/-}$, and $\mathrm{Pkd}_{111^{-/-}}$mice. Veterinary Pathol 47: $120-131$.

Walz G, Budde K, Mannaa M, Nurnberger J, Wanner C, Sommerer C, Kunzendorf U, Banas B, Horl WH, Obermuller N, et al. 2010. Everolimus in patients with autosomal dominant polycystic kidney disease. $N$ Engl J Med 363: $830-840$.

Watnick T, Germino G. 2003. From cilia to cyst. Nat Genet 34: $355-356$.

Watnick TJ, Torres VE, Gandolph MA, Qian F, Onuchic LF, Klinger KW, Landes G, Germino GG. 1998. Somatic mutation in individual liver cysts supports a two-hit model of cystogenesis in autosomal dominant polycystic kidney disease. Mol Cell 2: 247-251.

Weatherbee SD, Niswander LA, Anderson KV. 2009. A mouse model for Meckel syndrome reveals Mks1 is required for ciliogenesis and Hedgehog signaling. Hum Mol Genet 18: 4565-4575.

Wills ES, Roepman R, Drenth JP. 2014. Polycystic liver disease: Ductal plate malformation and the primary cilium. Trends Mol Med 20: 261-270.

Wong SY, Seol AD, So PL, Ermilov AN, Bichakjian CK, Epstein EH Jr, Dlugosz AA, Reiter JF. 2009. Primary cilia can both mediate and suppress Hedgehog pathway-dependent tumorigenesis. Nat Med 15: 1055-1061.

Wu G, D’Agati V, Cai Y, Markowitz G, Park JH, Reynolds DM, Maeda Y, Le TC, Hou H Jr, Kucherlapati R, et al. 1998. Somatic inactivation of $P k d 2$ results in polycystic kidney disease. Cell 93: 177-188.

Yoder BK, Hou X, Guay-Woodford LM. 2002. The polycystic kidney disease proteins, polycystin-1, polycystin-2, polaris, and cystin, are co-localized in renal cilia. J Am Soc Nephrol 13: 2508-2516.

Yoshiba S, Shiratori H, Kuo IY, Kawasumi A, Shinohara K, Nonaka S, Asai Y, Sasaki G, Belo JA, Sasaki H, et al. 2012. Cilia at the node of mouse embryos sense fluid flow for left-right determination via Pkd2. Science 338: 226-231.

Yu S, Hackmann K, Gao J, He X, Piontek K, Garcia-Gonzalez MA, Menezes LF, Xu H, Germino GG, Zuo J, et al. 2007. Essential role of cleavage of Polycystin-1 at G protein-coupled receptor proteolytic site for kidney tubular structure. Proc Natl Acad Sci 104: 18688-18693.

Yuan S, Zhao L, Brueckner M, Sun Z. 2015. Intraciliary calcium oscillations initiate vertebrate left-right asymmetry. Curr Biol 25: 556-567.

Zhang XM, Ramalho-Santos M, McMahon AP. 2001. Smoothened mutants reveal redundant roles for Shh and Ihh signaling including regulation of $\mathrm{L} / \mathrm{R}$ asymmetry by the mouse node. Cell 105: 781-792. 


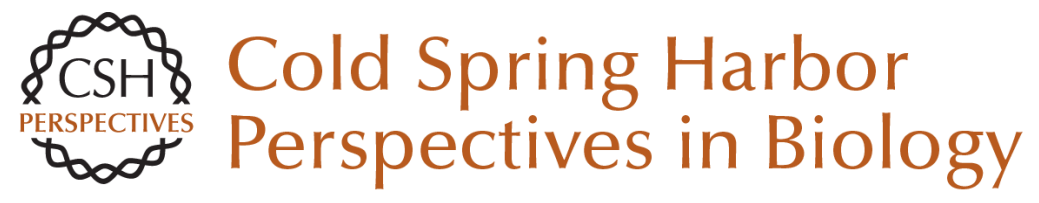

\section{Ciliary Mechanisms of Cyst Formation in Polycystic Kidney Disease}

Ming Ma, Anna-Rachel Gallagher and Stefan Somlo

Cold Spring Harb Perspect Biol 2017; doi: 10.1101/cshperspect.a028209 originally published online March 20, 2017

\section{Subject Collection Cilia}

Ciliary Mechanisms of Cyst Formation in

Polycystic Kidney Disease

Ming Ma, Anna-Rachel Gallagher and Stefan Somlo

Photoreceptor Cilia and Retinal Ciliopathies Kinga M. Bujakowska, Qin Liu and Eric A. Pierce

G-Protein-Coupled Receptor Signaling in Cilia Kirk Mykytyn and Candice Askwith

Evolution of Cilia David R. Mitchell

Transition Zone Migration: A Mechanism for Cytoplasmic Ciliogenesis and Postaxonemal Centriole Elongation

Tomer Avidor-Reiss, Andrew Ha and Marcus L. Basiri

Cilia and Obesity

Christian Vaisse, Jeremy F. Reiter and Nicolas F. Berbari

Posttranslational Modifications of Tubulin and Cilia

Dorota Wloga, Ewa Joachimiak, Panagiota Louka, et al.
Cilia in Left-Right Symmetry Breaking Kyosuke Shinohara and Hiroshi Hamada

Discovery, Diagnosis, and Etiology of Craniofacial Ciliopathies

Elizabeth N. Schock and Samantha A. Brugmann

Axoneme Structure from Motile Cilia Takashi Ishikawa

Cilia and Ciliopathies in Congenital Heart Disease Nikolai T. Klena, Brian C. Gibbs and Cecilia W. Lo

Sperm Sensory Signaling Dagmar Wachten, Jan F. Jikeli and U. Benjamin Kaupp

Primary Cilia and Coordination of Receptor Tyrosine Kinase (RTK) and Transforming Growth Factor $\beta$ (TGF- $\beta$ ) Signaling Søren T. Christensen, Stine K. Morthorst, Johanne B. Mogensen, et al.

Primary Cilia and Mammalian Hedgehog Signaling Fiona Bangs and Kathryn V. Anderson

For additional articles in this collection, see http://cshperspectives.cshlp.org/cgi/collection/

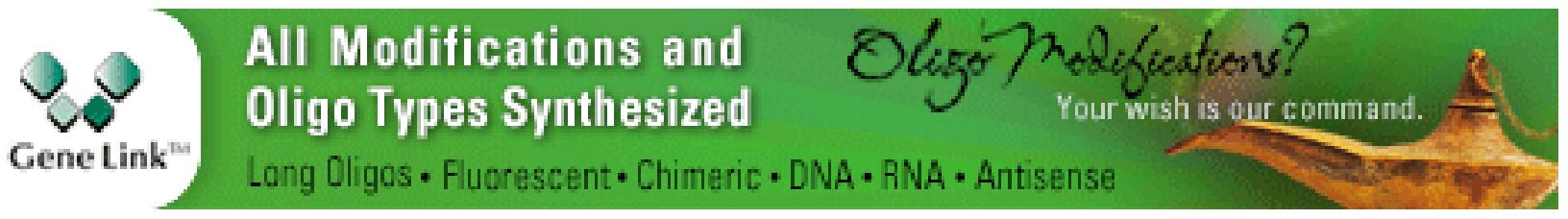


Radial Spokes--A Snapshot of the Motility Regulation, Assembly, and Evolution of Cilia and Flagella

Xiaoyan Zhu, Yi Liu and Pinfen Yang
Cilia and Mucociliary Clearance

Ximena M. Bustamante-Marin and Lawrence E. Ostrowski

For additional articles in this collection, see http://cshperspectives.cshlp.org/cgi/collection/

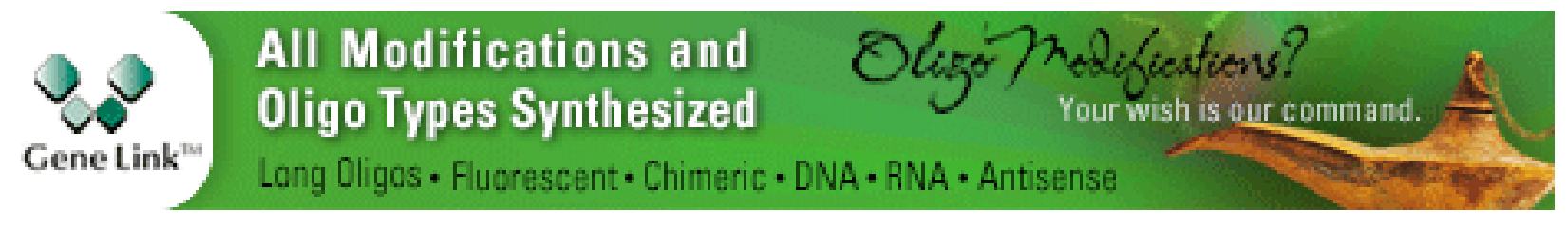

Copyright @ 2017 Cold Spring Harbor Laboratory Press; all rights reserved 